\title{
Vehicle Monitoring Using IOT
}

\author{
Parth C. Shah ${ }^{1}$, Rajkumar A. Purohit'2, Vishal M. Thakor ${ }^{3}$, Bhavik H. Parmar ${ }^{4}$, Mr.Kaushal Patel ${ }^{5}$, \\ Dr.Sheshang Degadwala ${ }^{6}$ \\ ${ }^{1-4}$ U.G. Student, Computer Engineering, Sigma Institute of Engineering, Bakrol, Vadodra, Gujarat, India \\ ${ }^{5}$ Assistant Professor, Computer Engineering, Sigma Institute of Engineering, Bakrol, Vadodra, Gujarat, India \\ ${ }^{6} \mathrm{Head}$ of Department Computer Engineering, Sigma Institute of Engineering, Bakrol, Vadodra, Gujarat, India
}

\begin{abstract}
Robbery of the vehicle is common thing now days, Robbers are smarter. They change the colour and number plate of the vehicle so it cannot be traced, there are many garages they buy stolen vehicle and sell their parts to different places.This all are common things in today's world. Rough Driving and accident happens daily at one or another place. Due to increased vehicle parking is also major issue so sometimes scratches or damage is occurred on the vehicle which are sometime not known till longer time. To avoid and know about any change/robbery of the vehicle. We will create an android application. Which will track user's vehicle when the user want to track the vehicle and when any one tries to break the user's vehicle lock our application will send notification and also track the vehicle through GPS. User can track his/her vehicle by using our application by entering username and password assigned to them. The vehicle tracking will only activate when the user will enter his user id and password while the vehicle is theft or to monitor vehicle. The application will show notification about damage part of the vehicle.
\end{abstract}

Keywords: Track, GPS, GSM, Vehicle, Notification.

\section{INTRODUCTION}

\subsection{PROJECT SUMMARY}

Vehicle monitoring system is made to provide security to all vehicle. This improves the security system for vehicles. This system enables the owner to observe and track his/her vehicle and can find out vehicle movement. In this system a hardware chip is attached in the vehicle in such a way that it is not visible to anyone. When the vehicle is stolen then the location data from tracking system can be used to find the location and notify the user. The vehicle monitoring system can detect un-authorized movement of the vehicle and then send alert to the owner.In case of accident if any major damage occurred then the notification will also be sent to the emergency contacts provided by the user. The user can also claim for insurance of the vehicle when the accident occurred and can renew the insurance policy when the policy expires. It also have feature that locates the nearby hospitals when the vehicle meets up with an accident. It also has feature of accident alert system, it detects damage if the damage is more then it detects the location of accident occurred and sends the data to specified mobile number. It also have feature to complain to police station about the stolen vehicle or accident occurred. 


\subsection{PURPOSE}

The purpose of system is to provide ease to vehicle tracking/monitoring. Our system will provide user's to track their vehicle when lost or theft. The exact location is indicating in latitude and longitude along with the exact navigated monitoring on google map. The system will track the vehicle's location and will send the location to the user. Our system will also provide other facilities like emergency call when accident occurs, the call or message will be send to the user's alternate emergency numbers. Our system will also provide the location of the nearby hospital. Our system will also give notifications of renewal on user's insurance policy or give information about other policy. System will also allow to claim the insurance.

System will also allow to do police complain of theft of vehicle.

\subsection{SCOPE OF SYSTEM}

This system will be helpful to user to track vehicle. This system will be helpful to police to Find users vehicle. This system will provide Damage notification to user. The insurance process will be easy. This system will help to find nearby hospital.

\subsection{OBJECTIVE}

- To Secure Vehicles of users.

- To Reduce Robbery of vehicles.

- To reduce number of Death Due to Accident.

- To make claim process easy.

- To reduce number of Accident due to Damage of vehicles.

\subsection{TECHNOLOGY AND LITERATURE REVIEW}

The Key Technologies used in developing the

Educational Social Network are:

\section{Clients:}

\section{Android OS}

2. Tools:

Android Studio
Microsoft Office

WebStrom 9.0.2

\section{METHODS AND MATERIAL}

\section{[1]. HARDWARE COMPONENTS:}

\section{A. GPS module}

The Global Positioning System in vehicle tracking systems is commonly used to provide users with information such as the location coordinates, speed, time, and so on, anywhere on Earth. In this work, a GPS module and a GPS receiver available from the Sparkfun website, is adopted to implement the in-vehicle device. The GPS module has the GPS receiver with antenna. There are two slide switches and one push button switch.

\section{B. GSM MODULE}

A GSM modem can be an external device or a PC Card Card. Typically, an external GSM modem is connected to a computer through a serial cable or a USB cable. A GSM modem in the form of a PC Card Card is designed for use with a laptop computer. It should be inserted into one of the PC Card Card slots of a laptop computer.Like a GSM mobile phone, a GSM modem requires a SIM card from a wireless carrier in order to operate.As mentioned in earlier sections of this SMS tutorial, computers use AT commands to control modems. Both GSM modems and dial-up modems support a common set of standard AT commands. You can use a GSM modem just like a dial-up modem.

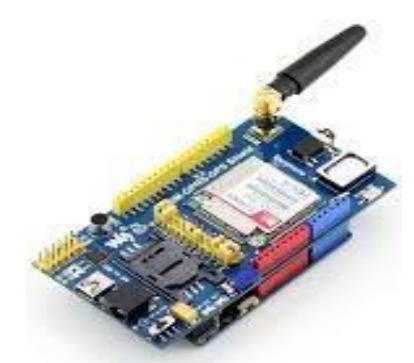

Figure 1. GPS and GSM Module 
III.SYSTEM ANALYSIS

\subsection{HARDWARE AND SOFTWARE}

\section{REQUIREMENTS (MINIMUM REQUIREMENTS TO RUN YOUR SYSTEM)}

\subsubsection{Hardware Requirements:}

- Table I. Hardware Requirement

\begin{tabular}{|c|c|}
\hline COMPONENT & MINIMUM REQUIREMENTS \\
\hline PROCESSOR & Core intel i3 \\
& Processor. \\
\hline RAM & 4GB RAM \\
\hline HDD & 320 GB HDD \\
\hline MOUSE & ANY MOUSE \\
\hline KEYBOARD & 120 KEYS \\
\hline MONITOR & LCL or TFT MONITOR \\
\hline
\end{tabular}

- Software Requirements:

- Table II Software Requirement

\begin{tabular}{|l|l|}
\hline \multicolumn{1}{|c|}{ COMPONENT } & \multicolumn{1}{c|}{$\begin{array}{c}\text { TOOLS OR } \\
\text { TECHNOLOGY }\end{array}$} \\
\hline Operating System & Windows 7-8 \\
\hline Front End & Ionic Android \\
\hline Back End & Microsoft SQL Server- \\
& 2008 \\
\hline Application & Microsoft Visual Studio \\
& 2010 \\
\hline
\end{tabular}

\subsubsection{STUDY OF CURRENT SYSTEM}

In current system the work done is totally manual and based on paper work. It can be huge load for human. The system consumes huge amount of time for getting the data and it is not sure whether the data is proper or not. In the current sometimes the data is lost because it is done on papers only.

\subsubsection{PROBLEM AND WEAKNESS OF CURRENT SYSTEM}

- In the current system, the whole work is done manually and based on paper.

- So the current system can be huge load to human.

- In this system sometimes, data may be lost.

- This system consumes huge amount of time for getting the data.

- The obtained data is real or not is not sure.

- The data sometimes may be lost because it is based on only paper work.

\subsubsection{FEATURES OF NEW SYSTEM}

- A person can easily track his/her vehicle.

- Person gets damage notification in vehicle.

- User can directly file complain about the robbery of vehicle to police.

- User can find nearest hospital at the place of accident.

- User can also take or renew insurance policy.

\section{SUMMARY OF PROJECT}

\subsection{LIMITATION}

- Required internet.

- Smart phone with camera is compulsory.

\subsection{FUTURE ENHANCEMENT}

- We can use bomb detector.

- With the help of high sensitivity vibration sensors, we can detect the accident.

- Previous navigating positions are limited but we can navigate up to $\mathrm{N}$ number of location by increasing its memory.

- We can increase more accuracy.

\subsection{Implementation}

In the implementation of vehicle monitoring using IOT controlled by microcontroller, software(android) and hardware. In our project we are going to make a 
hardware which will monitor the vehicle of the user and send notification to the user through our mobile (Android) app. Our app will also allow the user to complain about the theft or accident of the vehicle. Our app will also provide the user to renewal of the insurance. User can also claim the insurance easily. user can track the vehicle location using our application. Our system will have two sensors one will notify the accident by the vibrations effect and other will notify the location of the vehicle. The gps and gsm will help to send the current location through message.This modem will contain gps and gsm modem. The android application will be used to monitor activities of vehicle.

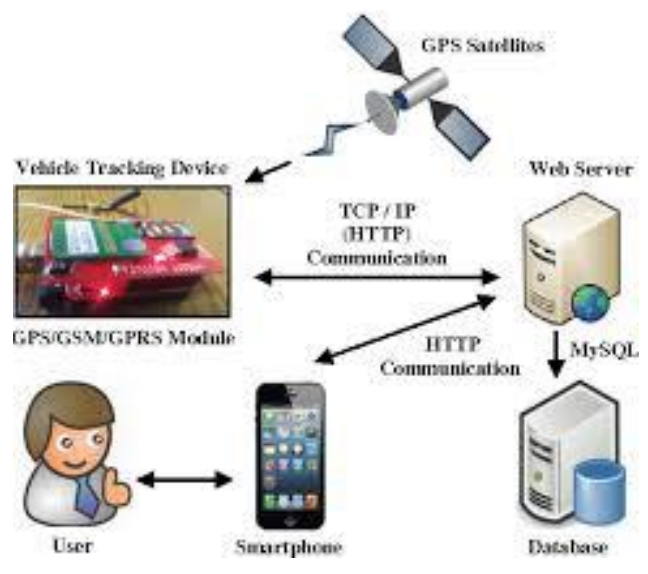

Figure 2.System Flow

\section{CONCLUSION}

This system is complete solution for the vehicle monitoring and controlling the vehicle function by using sensor and android application. System can also track the vehicle by using GPS if any part of vehicle damage and accident then it will be notify by the sensor to the user system.

\section{REFERENCES}

[1]. Object Oriented Analysis and Design with UML, Author:- Michael blaha, Publication:Pearson,Edition: - 4th Revised Edition
[2]. Database System Concepts, Author:- Abraham Silberschat, Henry F. Korth , S. SudarshanPublication:- McGraw Hill International Publication, Edition:- 6th Edition

[3]. Software Engineering:- Theory and Practice by Pearson Education, India

[4]. http://challengeforsustainability.org/toolkit/ener gy-efficiency/motion-sensors/

[5]. http://www.gomog.com/allmorgan/CAMBER_C ASTOR_TOE.html

[6]. http://education.rec.ri.cmu.edu/content/electron ics/boe/ir_sensor/1.html

[7]. https://www.exploreembedded.com/wiki/Settin g_up_GPRS_with_SIM800L

[8]. https://developers.google.com/maps/documentat ion/directions/

[9]. https://www.sparkfun.com/products/9607

[10]. https://www.sparkfun.com/products/10709

[11]. Aaron Smith, "Nearly half of American adults are Smartphone", http://pewinternet.org/ $/$ media/Files/Reports/20 12/Smartphone\%20owne rship\%202012.pdf , 2012

[12]. Jithin V mohan, Minu Balan, Sharoon Thomas, and Lynn Mariette Mendonza, "Fleet Mangement System", B.Tech Degree Thesis, College of Engineering, Munnar, Idukki, Kerala, India, 2009

[13]. Mohammad A. Al-Khedher, "Hybrid GPS-GSM Localization of Automobile Tracking System", International Journal of Computer Science \& Information Technology (IJCSIT) Vol 3, No 6, Dec 2011

[14]. Saed Tarapiah, Shadi Atalla, and Rajaa AbuHania, "Smart On-Board Transportation Management System Using GPS/GSM/GPRS Technologies to Reduce Traffic Violation in Developing Countries",International Journal of Digital Information and Wireless Communications (IJDIWC) 3(4): 96-105, The Society of Digital Information and Wireless Communications, 2013 (ISSN: 2225-658X) 
[15]. Muruganandham, "Real Time Web based Vehicle Tracking using GPS”,

[16]. World Academy of Science, Engineering and Techonogy, 37, 2010

[17]. R.Ramani,S.Valarmathy, N.SuthanthiraVanitha, S.Selvaraju, and M.Thiruppathi, "Vehicle Tracking and Locking Sytem Based on GSM and GPS”, I.J. Intelligent Systems and Applications, 2013, 09, 86-93

[18]. G.Kiran Kumar, A. Mallikarjuna Prasad, "Public Transportation Mangement Service using GPSGSM", International Journal of Research in Computer and Communication Technology, IJRCCT, ISSN- 2278-5841, Vol-1, Issue -3, Aug 2012.

[19]. Ambade Shruti Dinker and S. A Shaikh, "Design and Implementation Of vehicle Tracking System Using GPS", Joural of Information Engineering and Applications, Vol 1, No.3, 2011

[20]. Eddie Chi-Wah Lau, "Simple Bus Tracking System", Journal of Advanced Computer Science and Technology Research, Vol3, No.1, 2013

[21]. Montaser N. Ramadan, Mohammad A. AlKhedher, and Sharaf A. Al- Kheder, "Intelligent Anti-Theft and Tracking Sytem for Automobiles", International Journal of Machine Learning and Computing Vol.2 No. 1, February 2012.

[22]. Swapna Raghunath, P.Visalakshmi, and Karam Sridhar, "GPS Datum Conversion and Kalman Filtering for Reducing Positional Errors", Asian Journal Of Computer Science And Information Technology1: 5 (2011) 141- 145.

[23]. Ahmed ElShafee, Mahmoud EIMenshawi, and Mena Saeed, "Integrating Social Network Services with Vehicle Tracking Technologies", International Journal of Advanced Computer Science and Applications,Vol. 4, No. 6, 2013

[24]. "Arduino microcontroller",http://arduino.cc

[25]. "GPSmodule", https://www.sparkfun.com/products/10709

[26]. "TinyGPS", http://arduiniana.org/libraries/tinygps/
[27]. "GSM/GPRS

module", https://www.sparkfun.com/products/9607

[28]. "SM5100B AT Command", https://www.sparkfun.com/datasheets/CellularS hield/SM5100B\%20TCP IP\%20App\%20Note.pdf

[29]. https://www.sparkfun.com/datasheets/Cellular\% 20Modules/CEL-

09533-

AT\%20Command_V1[1].0.0-1.pdf

[30]. "The Google Directions API" , https://developers.google.com/maps/documentat ion/directions 